\title{
Chemokines in Type 1 Diabetes Mellitus
}

\begin{abstract}
Xiongfeng Pan ${ }^{1}$, Atipatsa C. Kaminga ${ }^{1,2}$, Sanjay Kinra ${ }^{3}$, Shi Wu Wen ${ }^{4,5,6}$, Hongying Liu ${ }^{1}$, Xinrui Tan $^{7 *}$ and Aizhong Liu ${ }^{1 *}$

1 Department of Epidemiology and Health Statistics, Xiangya School of Public Health, Central South University, Changsha, China, ${ }^{2}$ Department of Mathematics and Statistics, Mzuzu University, Mzuzu, Malawi, ${ }^{3}$ Departmentof Non-Communicable Disease Epidemiology, London School of Hygiene and Tropical Medicine, London, United Kingdom, ${ }^{4}$ Ottawa Hospital Research Institute (OMNI) Research Group, Ottawa Hospital Research Institute, Ottawa, ON, Canada, ${ }^{5}$ Department of Obstetrics and Gynaecology, University of Ottawa Faculty of Medicine, Ottawa, ON, Canada, ${ }^{6}$ School of Epidemiology and Public Health, University of Ottawa Faculty of Medicine, Ottawa, ON, Canada, ${ }^{7}$ Department of Pediatrics, the Second Xiangya Hospital, Central South University, Changsha, China
\end{abstract}

OPEN ACCESS

Edited by: Annalisa Del Prete, University of Brescia, Italy

Reviewed by: Silvia Martina Ferrari, University of Pisa, Italy Federico Diaz-Gonzalez, University of La Laguna, Spain Urs Christen,

Goethe University Frankfurt, Germany

*Correspondence: Xinrui Tan

xinruitan@csu.edu.cn Aizhong Liu lazroy@live.cn

Specialty section: This article was submitted to Cytokines and Soluble Mediators in Immunity, a section of the journal Frontiers in Immunology

Received: 02 April 2021 Accepted: 02 December 2021 Published: 15 February 2022

Citation:

Pan X, Kaminga AC, Kinra S, Wen SW, Liu H, Tan X and Liu A (2022) Chemokines in Type 1 Diabetes Mellitus.

Front. Immunol. 12:690082. doi: 10.3389/fimmu.2021.690082
Background: Previous studies suggested that chemokines may play an important role in the formation and mediation of immune microenvironments of patients affected by Type 1 Diabetes Mellitus (T1DM). The aim of this study was to summarise available evidence on the associations of different chemokines with T1DM.

Methods: Following PRISMA guidelines, we systematically searched in PubMed, Web of Science, Embase and Cochrane Library databases for studies on the associations of different chemokines with T1DM. The effect size of the associations were the standardized mean differences (SMDs) with corresponding 95\% confidence intervals (Cls) of the chemokines concentrations, calculated as group differences between the T1DM patients and the controls. These were summarized using network meta-analysis, which was also used to rank the chemokines by surface under cumulative ranking curve (SUCRA) probabilities.

Results: A total of 32 original studies on the association of different chemokines with T1DM were identified. Fifteen different chemokine nodes were compared between 15,683 T1DM patients and 15,128 controls, and 6 different chemokine receptor nodes were compared between 463 T1DM patients and 460 controls. Circulating samples (blood, serum, and plasma) showed that concentrations of CCL5 and CXCL1 were significantly higher in the T1DM patients than in the controls (SMD of 3.13 and 1.50, respectively). On the other hand, no significant difference in chemokine receptors between T1DM and controls was observed. SUCRA probabilities showed that circulating CCL5 had the highest rank in T1DM among all the chemokines investigated.

Conclusion: The results suggest that circulating CCL5 and CXCL1 may be promising novel biomarkers of T1DM. Future research should attempt to replicate these findings in longitudinal studies and explore potential mechanisms underlying this association. 


\section{INTRODUCTION}

Type 1 diabetes mellitus (T1DM) affects about 11-22 million people worldwide and accounts for $90 \%$ of childhood diabetes $(1,2)$. The global incidence and prevalence of T1DM have markedly increased in recent years, as have their serious complications, resulting in a considerable health burden to individuals living with T1DM worldwide (3). Specifically, T1DM is an autoimmune disorder characterized by destruction of the pancreatic $\beta$ cells (4). In this regard, dysfunction of the $\beta$ cells leads to severely impaired, or absent insulin secretion, and hence patients need long-term insulin treatment to survive. However, the immunological trigger and the exact pathogenesis of T1DM remain unknown (5). It should be noted that long-term insulin treatment for T1DM has several other limitations (3). For example, although this treatment partly addresses the paradoxical and pathophysiological excess of glucagon, it is associated with weight gain; which adversely affect hypertension, cardiovascular disease, and atherosclerosis risk profile $(6,7)$. Therefore, studies have been conducted to explore new insulin adjunct therapies for T1DM. The findings of these studies showed an increasing body of evidence linking T1DM to pancreatic immune microenvironment (8-10).

Specifically, preclinical work has identified chemotactic cytokines (chemokines) as an important group of first inflammatory mediators, expressed after pancreatic early damage, which act to coordinate immune cells and attract them to the immune microenvironment of ongoing inflammation (11). A further study of the pancreatic immune microenvironment indicated a possible role of T helper 1 (Th1) cells in the progress of $\beta$ cells destruction $(8,12)$. Moreover, the autoreactive memory T cells (CD4+ and CD8+ T cells) may lead to the progressive destruction of pancreatic $\beta$ cells (13). In this process, chemokines mediate the rapid recruitment of activated Th1, neutrophils, macrophages, and natural killer (NK) cells, which increase the initial damage, hence mediating the killing of $\beta$ cells and promoting further inflammation (10).

Considering that chemokines can be divided into four subfamilies, C, CC, CXC, and CX3C, according to their Nterminal cysteine motifs, the role of chemokines and their receptors in T1DM may be multifaceted (11). For example, previous studies indicated that the CCL4-CCR5 axis, CXCL10CXCR3 axis, and CXCR1/2 pathway have the ability to predominantly attract the more aggressive Th1 T-cells, which increase the initial damage, hence mediating the killing of $\beta$ cells and promote further inflammation $(9,10,14)$. On the other hand, the CXCL12-CXCR4 axis and CXCL12-CXCR7 have the ability to sustain local immune-isolation, and can stimulate the regeneration, proliferation, and survival of $\beta$ cells $(15,16)$. This evidence supports the hypothesis that there is a crosstalk between different chemokines that are involved in the in situ inflammatory responses, potentially contributing to both the initial destruction of $\beta$ cells and the intensified progression to

Abbreviations: BMI, Body Mass Index; RIA, Radioimmunoassay; ELISA, Enzyme linked immunosorbent assay; USA, United States of America; UK, United Kingdom; T1DM, Type-1diabetes mellitus. overt T1DM. Therefore, targeted immune intervention of critical chemokines may prevent the subsequent development of the autoimmunity. However, previous studies exploring chemokine biomarkers for T1DM have used multiple unstandardised names for chemokines and frequently found conflicting results, which have thus far not been summarized using meta-analysis. Therefore, this study aimed to quantitatively analyze the concentrations of different chemokines in T1DM, using highquality meta-analysis techniques involving as many chemokine names as possible.

\section{METHODS}

\section{Search Strategy and Selection Criteria}

This meta-analysis was conducted according to the Preferred Reporting Items for Systematic Reviews and Meta-Analyses (PRISMA) guidelines, and standard procedures provided in the Cochrane Handbook (17). In addition, the protocol for this meta-analysis was registered in the PROSPERO database (registration number: CRD42019148305 (https://www.crd.york. ac.uk/PROSPERO).

Following PRISMA guidelines, two authors (XP and AK) independently searched in the Web of Science, PubMed, Embase, and Cochrane Library, for relevant studies published not later than June 30, 2020. Additionally, the reference lists of selected studies were manually checked to find more relevant studies. Studies not written in English and grey literature were also included to avoid publication bias. Experienced librarians designed and adjusted a broad but highly structured search strategy. Specifically, professional and variant names were included to identify as many chemokines as possible according to the immunologists' recommendations. Keywords for the search strategy also included various combinations of terms for T1DM, juvenile-onset diabetes mellitus and autoimmune diabetes. In addition, Boolean operators, truncation, and wildcards were implemented to allow for variant chemokines and T1DM names. The full search strategy is available in the Appendix 1 of Supplementary Information.

\section{Study Selection}

Studies were selected for data extraction based on the Population, Intervention/Exposure, Comparison, Outcome, and Study design (PICOS) framework. In this regards, the Population was patients with or without T1DM, Intervention/Exposure was patients with T1DM, Comparison was subjects without T1DM, Outcome was chemokines concentrations, and the Study design included longitudinal, cross-sectional, and case-control study designs. The inclusion criteria were: (1) studies measured concentrations of chemokines in patients with T1DM and controls, or these data could be obtained upon request from the corresponding authors; (2) studies reported methods for diagnosing T1DM; (3) controls did not meet diagnostic criteria for T1DM; and (4) study designs were longitudinal, crosssectional, or case-control. The exclusion criteria were: (1) 
in vitro and non-human studies; (2) participants had a comorbid or additional metabolic disorders; (3) studies focused on stimulated levels of chemokines (these studies measured the consequences of pharmacological challenge as opposed to basal immune activity); and (4) conference papers, case reports, letters, or reviews were excluded.

\section{Data Extraction}

Two reviewers (XP and AK) independently extracted the data using a custom data extraction template. First, Endnote (version x9.1) was used to remove duplicate data, and then the EpiData (version 3.0) was used to extract data. All data were stored in a custom data extraction template (Microsoft Excel 2019). For this study, the following characteristics of eligible studies were extracted: (1) surname of the first author and year of publication; (2) region of the research origination; (3) sample characteristics such as sample materials; (4) chemokines sample detection method; (5) characteristics of study subjects such as body mass index (BMI), race, duration of diabetes, age, sex, waist circumference (WC), systolic blood pressure (SBP), and diastolic blood pressure (DBP); (6) biochemical indicators such as fasting plasma glucose (FPG), C-reactive protein (CRP), low-density lipoprotein (LDL), high-density lipoprotein (HDL), triglycerides (TG), haemoglobin Alc (HbAlc) and creatinine; and (7) the mean and standard deviation [mean $( \pm$ s.d.)] of chemokine concentrations of study subjects. Two independent reviewers sought missing data through request from corresponding authors via emails. When a request was not successful, alternative techniques were used for data extraction. For example, the Engauge Digitizer (version 4.1) was used for data extraction when data were presented only in graphical format. Any disagreements regarding data inclusion were settled by consensus involving the third reviewer (AL). Finally, the Newcastle-Ottawa Quality Assessment Scale (NOS) was used to assess the risk of bias and the quality of the eligible studies as recommended by the Cochrane Collaboration. Moreover, studies that scored greater than or equal to the median quality score $(\geq 4)$ were considered having low risk of bias $(18,19)$.

\section{Statistical Analysis}

The package meta of $\mathrm{R}$ software (version 3.5.2) was used for meta-analysis, and Stata (version 15.0) was used for network meta-analysis $(20,21)$. The effect size was estimated as standardized mean difference (SMD) with corresponding 95\% confidence interval (CI), using Cohen's d. Given racial and assay methods heterogeneity, when measuring chemokines, the random-effects model was used to summarize the effect size (22-24). The random-effects model includes both within-study and between-studies variation in the assessment of the uncertainty of results $(25,26)$. This meta-analysis method is more conservative and is chosen if significant heterogeneity is expected. Statistical heterogeneity between studies was assessed using the Cochrane's Q test (Chi-squared test) (27). Further, the $I^{2}$ statistic was calculated to quantify this statistical heterogeneity (28). The $I^{2}$ ranges from $0 \%$ to $100 \%$, with $100 \%$ indicating maximal heterogeneity and $0 \%$ no heterogeneity (29).
If significant heterogeneity exists, it suggests variability in the study characteristics. The likely sources of heterogeneity in this study included BMI, race, HbAlc, age, sex, and duration of diabetes. Therefore, whenever data were adequate, these variables were investigated by subgroup analysis to explore sources of heterogeneity. Sensitivity analyses were performed to explore the impact of an individual study on the estimated effect size, SMD. This was accomplished by omitting each study at a time (19). Lastly, the funnel plot and the Egger's test were used to assess publication bias when at least 10 studies per comparison were available (30).

Network meta-analysis was conducted by the Markov chain Monte Carlo method in Stata (version 15.0), using the selfprogrammed Stata routines and network commands, to compare the effects of multiple correction chemokines. The random effects model was evaluated before conducting the network metaanalysis. Thus, if the random effects model satisfied some conditions, network meta-analysis was performed in a frequentist framework, with consistency assumption (31). The first 10,000 iterations were discarded, and additional 50,000 iterations were executed (20). Moreover, vague priors were used in the network meta-analysis. A common heterogeneity value across all comparisons was assumed, and the average residual deviation was used to estimate the Goodness-of-fit. Standardized mean differences (SMDs) along with their 95\% CI were presented for continuous data in the networks. Meanwhile, for each of the chemokines, the surface under cumulative ranking curve (SUCRA) was used to estimate the relative rankings of the various chemokines (32). Thus, chemokines with higher SUCRA values were considered the most potent chemokines. The value, $S U C R A=0$, indicated the worst significant difference, whereas $S U C R A=1$ indicated the best significant difference. A p value (two-sided) $<0.05$ indicated statistically significant results in all the statistical tests.

\section{RESULTS}

\section{Literature Search}

The utilization of the systematic search of electronic databases and manual searching of references yielded a total of 3,732 studies, of which 903 were from the PubMed, 1,228 from the Embase, 768 from the Web of Science, and 833 from the Cochrane library. After duplicates were removed, 3,368 abstracts were reviewed and this resulted in the exclusion of 3,113 studies. Following a full review of 255 studies, 32 met the inclusion criteria for this systematic review and meta-analysis (Appendix 2).

\section{Characteristics of Eligible Studies}

Characteristics of included studies are shown in Table $\mathbf{1}$ and Appendix 3. These studies were published between 2001 and 2019. Nine different CC chemokine nodes were compared between 10,013 T1DM patients and 9,713 controls, while 6 different CXC chemokine nodes were compared between 5,670 T1DM patients and 5,415 controls. Further, 6 different 
TABLE 1 | Characteristics of included studies.

\begin{tabular}{|c|c|c|c|c|c|c|c|c|c|}
\hline Study & & Material & Country & Male (\%) & NOS & BMI & Mean Age & Detection method & Duration of diabetes \\
\hline Abke et al. 2006 & (33) & Blood & Germany & $\mathrm{O}(0.0 \%)$ & 8 & $22.3(19.5-31)$ & $\begin{array}{l}36.5(18.0- \\
46.0)\end{array}$ & ELISA & $13.5(7-34)$ years \\
\hline Antonelli et al. 2008 & (34) & Serum & Italy & $49(51 \%)$ & 7 & $17.1 \pm 3.2$ & $8.2 \pm 3.7$ & ELISA & NR \\
\hline Berg et al. 2010 & (35) & Blood & Sweden & $47(56.6 \%)$ & 7 & NR & $\begin{array}{l}9.5(1.6- \\
16.4)\end{array}$ & ELISA & NR \\
\hline Cetinkalp et al. 2015 & $(36)$ & Blood & Turkey & $9(36.0 \%)$ & 6 & 25.2(3.6) & $33.3 \pm 9.2$ & ELISA & NR \\
\hline Chatzigeorgiou et al. 2010 & $(37)$ & Plasma & Greece & $17(38.6 \%)$ & 8 & $20.48 \pm 1.03$ & $11.5 \pm 0.7$ & ELISA & $50.76 \pm 11.61$ months \\
\hline Dakovic et al. 2013 & (38) & Serum & Serbia & $9(45.0 \%)$ & 7 & NR & $12.8 \pm 3.9$ & ELISA & $5.78 \pm 3.45$ years \\
\hline Ellina et al. 2012 & (39) & Plasma & Greece & $13(43.3 \%)$ & 7 & $20.65 \pm 0.95$ & $11.5 \pm 0.6$ & ELISA & $\begin{array}{l}57.53 \pm 19.61(0-184) \\
\text { months }\end{array}$ \\
\hline Erbağci et al. 2001 & $(40)$ & Blood & USA & $N R$ & 5 & $N R$ & NR & ELISA & $N R$ \\
\hline Gabbay et al. 2012 & $(41)$ & Serum & Brazil & $35(42 \%)$ & 8 & $18.6 \pm 2.6$ & $13.0 \pm 5.0$ & ELISA & 3 months \\
\hline Giulietti et al. 2007 & $(42)$ & Blood & Belgium & $6(46.15 \%)$ & 8 & $\begin{array}{l}31.3(24.5- \\
40.0)\end{array}$ & $\begin{array}{l}\text { 62.0(48.0- } \\
81.0)\end{array}$ & ELISA & 8.8 years (3-29 years) \\
\hline Guan et al. 2011 & $(43)$ & Blood & China & $\mathrm{O}(0.0 \%)$ & 5 & NR & $N R$ & ELISA & NR \\
\hline Hakimizadeh et al. 2013 & $(44)$ & Blood & Iran & $209(51.0 \%)$ & 7 & NR & $30.0 \pm 5.0$ & ELISA & $10 \pm 4$ years \\
\hline Heier et al. 2015 & $(45)$ & Blood & Norway & $156(49.68 \%)$ & 8 & 20.8(3.9) & $13.7(2.8)$ & ELISA & $5.5 \pm 3.4$ years \\
\hline Huang et al. 2012 & $(46)$ & Serum & China & $155(53.45 \%)$ & 7 & NR & $26.4(0.9-61)$ & $\mathrm{RIA}$ & 1.4 months (0-12 months) \\
\hline Ismail et al. 2016 & $(47)$ & Blood & Egypt & 13(33.3\%) & 8 & $23.51 \pm 4.14$ & $14.6 \pm 2.6$ & ELISA & $5.36 \pm 3.32$ years \\
\hline Jamali et al. 2013 & $(48)$ & Blood & Iran & 55 (51\%) & 7 & NR & $45.0 \pm 9.5$ & ELISA & $10 \pm 4$ years \\
\hline Lappin et al. 2015 & (49) & Blood & UK & $10(35.7 \%)$ & 7 & NR & $35.0 \pm 10.0$ & ELISA & $N R$ \\
\hline Lohmann et al. 2002 & (50) & Blood & Germany & NR & 5 & NR & $9.9 \pm 4.1$ & ELISA/FLA & $3.2 \pm 1.2$ years \\
\hline Melo et al. 2016 & $(51)$ & Serum & Canada & $10(27.8 \%)$ & 8 & $23.6 \pm 4.9$ & $14.5 \pm 1.4$ & Luminex & $8.0 \pm 3.4$ years \\
\hline Nicolett et al. 2002 & $(52)$ & Blood & India & $\mathrm{O}(0.0 \%)$ & 6 & 25.7 & 27.6 & ELISA & NR \\
\hline Nieminen et al. 2012 & (53) & Blood & Finland & NR & 5 & NR & $7.3 \pm 1.4$ & Luminex/qPCR & NR \\
\hline Pellegrini et al. 2017 & $(54)$ & Blood & Italy & $10(52.63 \%)$ & 7 & NR & $\begin{array}{l}34.0(6.0- \\
65.0)\end{array}$ & ELISA/RT-PCR & $20(0-37)$ months \\
\hline Pham et al. 2012 & $(55)$ & Serum & Germany & $62(68.88 \%)$ & 8 & $\begin{array}{l}26.1(22.8- \\
29.2)\end{array}$ & $\begin{array}{l}43.2(35.5- \\
53.3)\end{array}$ & Multiplex & $1.0(0.2-1.6)$ years \\
\hline Powell et al. 2018 & $(56)$ & Blood & UK & $5(50 \%)$ & 6 & NR & $\begin{array}{l}33.4(23.0- \\
44.0)\end{array}$ & ELISA/FLA & $N R$ \\
\hline Purohit et al. 2015 & $(57)$ & Blood & USA & $266(47.5 \%)$ & 8 & NR & $24.6 \pm 16.5$ & Multiplex & $10.7 \pm 9.8$ years \\
\hline Rosa et al. 2008 & (58) & Blood & USA & $13(61.9 \%)$ & 7 & $65.4 \pm 5.4$ & $13.4 \pm 0.3$ & Luminex & NR \\
\hline Sickle et al. 2009 & (59) & Blood & USA & $8(47.05 \%)$ & 8 & $23.5 \pm 4.1$ & $15.9 \pm 1.8$ & $\mathrm{RIA}$ & $6.7 \pm 2.2$ years \\
\hline Sochet et al. 2017 & $(60)$ & Serum & Canada & $25(49 \%)$ & 7 & NR & $\begin{array}{l}14.8(10.9- \\
16.8)\end{array}$ & Luminex & $6.7(2.0-13.9)$ years \\
\hline Vorobjova et al. 2019 & $(61)$ & Serum & Estonia & $6(66.66 \%)$ & 6 & NR & $\begin{array}{l}8.5(4.0- \\
13.1)\end{array}$ & Multiplex & NR \\
\hline Wolkow et al. 2008 & (62) & Blood & USA & NR & 5 & NR & $\begin{array}{l}32.0(25.0- \\
37.0)\end{array}$ & Luminex & NR \\
\hline Yamamura et al. 2019 & (63) & Serum & Japan & NR & 5 & $23.5 \pm 4.1$ & $53.5 \pm 15.0$ & ELISA & $12.1 \pm 9.3$ years \\
\hline Zóka et al. 2015 & (64) & Blood & Hungary & $16(47.05 \%)$ & 8 & $\begin{array}{l}23.61(22.13- \\
25.08)\end{array}$ & $\begin{array}{l}32.7(29.4- \\
35.9)\end{array}$ & Luminex/FLA & 14.6 years \\
\hline
\end{tabular}

NR, not report; BMI, Body Mass Index; RT-PCR, Real-time polymerase chain reaction; qPCR, Quantitative real-time polymerase chain reaction; FLA, Fluorescein-labeled antibody surface protein measurements; RIA, Radioimmunoassay; ELISA, Enzyme linked immunosorbent assay; USA, United States of America; UK, United Kingdom.

chemokine receptor nodes were compared between 463 T1DM patients and 460 controls. As regards sample materials, 21 studies examined chemokines from blood samples, 9 from serum samples, and 2 from plasma samples. Five studies were conducted in the United States of America; 3 in Germany; 2 in each of the countries, Canada, China, Greece, Iran, Italy, and UK; and 1 in each of the countries, Belgium, Brazil, Egypt, Estonia, Finland, Hungary, India, Japan, Norway, Serbia, Sweden, and Turkey. To determine chemokines, 21 studies used enzyme linked immunosorbent assay (ELISA), 6 used Luminex, 3 used Multiplex, and 2 used radioimmunoassay (RIA). The real-time polymerase chain reaction (RT-PCR) was used to detect the mRNA expression of chemokine receptor. The NOS scores of study quality assessment varied between 5 and 8 , with ten studies classified as moderate quality and 22 as high quality.

Appendix 4 summarizes the correspondence between the classification of chemokines and their receptors. The XCL1 and XCL2 belong to the $\mathrm{C}$ subfamily of chemokines; the CCL1, CCL2, CCL3, ..., CCL26, CCL27, and CCL28 belong to the CC subfamily of chemokines; the CXCL1, CXCL2, CXCL3, ..., CXCL14, CXCL15, and CXCL16 belong to the CXC subfamily of chemokines; and the CX3CL1 belongs to the CX3C subfamily of chemokines. Moreover, the XCR1 belongs to the XCR subfamily of chemokine receptors; the CCR1, CCR2, CCR3, ..., CCR8, CCR9, and CCR10 belong to the CCR subfamily of chemokine receptors; and the CXCR1, CXCR2, CXCR3, CXCR4, 
CXCR5, CXCR6, CXCR7, and CX3CR belong to the CXCR subfamily of chemokine receptors. Appendix 5 summarizes the distribution of immune cells corresponding to different chemokine receptor types (e.g., Th1 cells, Th17 cells, CD4+T cells, CD8+T cells, Treg cells, basophils, dendric cells, monocytes, macrophages, and NK cells).

\section{Main Outcomes}

A total of 19,726 participants (10,013 T1DM cases and 9,713 controls) were included for analyzing the effect of CC chemokines on T1DM. Concentrations of CC chemokines in the circulating samples (blood, serum, and plasma) were significantly higher in the T1DM patients than in the controls ( $\mathrm{SMD}=0.80$; $95 \% \mathrm{CI}$ : 0.41 to 1.19 ; Figure 1). Concentration of circulating CCL5 was significantly higher in the T1DM patients than in the controls (SMD=3.13; 95\% CI: 2.02 to 4.23; Figure 1). Nevertheless, significant heterogeneity was observed across the included studies $\left(I^{2}=99 \%\right)$. However, there was a significant decrease in the concentrations of circulating CCL7 in the T1DM patients than in the controls $(\mathrm{SMD}=-0.37 ; 95 \% \mathrm{CI}$ : -0.44 to -0.49 ; Figure 1). Evidence of heterogeneity across the included studies was not present $\left(I^{2}=0 \%\right)$. There were no significant differences in the concentrations of other CC chemokines between the T1DM and control subjects. Furthermore, a total of 11,085 participants (5,670 T1DM cases and 5,415 controls) were included in the analysis of the effect of CXC chemokines on T1DM. Concentrations of circulating CXCL1 were significantly higher in the T1DM patients than in the controls $(\mathrm{SMD}=1.50 ; 95 \% \mathrm{CI}: 0.53$ to 2.47 ; Figure 2). However, significant heterogeneity was observed across the included studies $\left(I^{2}=95 \%\right)$. Also, there was a significant decrease in the concentrations of circulating CXCL9 in the T1DM patients than in the controls $(\mathrm{SMD}=-1.40 ; 95 \% \mathrm{CI}$ : -2.48 to -0.32 ; Figure 2). Similarly, significant heterogeneity was observed across the included studies $\left(I^{2}=99 \%\right)$. There were no significant differences in the concentrations of other CXC chemokines between the T1DM and control subjects. As regards the effect of chemokine receptors on T1DM, a total of 923 participants (463 T1DM cases and 460 controls) were included in the analysis. There were no significant differences in the concentrations of any chemokine receptors between the T1DM patients and controls. Sensitivity analyses demonstrated that eliminating any single study had little effect on the overall SMD of the concentrations of chemokines or chemokine receptors between the T1DM patients and controls. Additionally, there was no obvious asymmetry in the funnel plot (Appendix 6), and the Egger's test was not significant $(\mathrm{p}=0.1139)$.

\section{Subgroup Analysis Outcomes}

\section{Subgroup Analysis for CC Chemokines}

Subgroup analysis by race revealed that, among the Asian subjects, the concentrations of CC chemokines differed significantly between the T1DM patients and controls $(\mathrm{SMD}=3.79$; $95 \% \mathrm{CI}: 1.38$ to 6.20 ; Table 2 ), but not among the Caucasian subjects. Similarly, subgroup analysis by sex revealed that, among the female subjects, the concentrations of $\mathrm{CC}$ chemokines differed significantly between the T1DM patients and controls ( $\mathrm{SMD}=0.68$; $95 \% \mathrm{CI}$ : 0.23 to 1.14 ; Table 2), but not among the male subjects. Furthermore, subgroup analysis by BMI found a significant difference in the concentrations of CC chemokines, between the T1DM patients and controls, among the study subjects with a BMI of at most 23.9 (SMD $=1.55 ; 95 \%$ CI: 0.67 to 2.43; Table 2), but not among those with a BMI > 23.9. Also, subgroup analysis by glycated haemoglobin status demonstrated a significant difference in the concentrations of CC chemokines, between the T1DM patients and controls, among the study subjects with $\mathrm{HbA1c}$ higher than $8 \%$ $(\mathrm{SMD}=2.09$; $95 \% \mathrm{CI}: 1.01$ to 3.18 ; Table 2$)$, but not among the study subjects with $\mathrm{HbAlc}$ lower than or equal to $8 \%$.

\section{Subgroup Analysis for CXC Chemokine}

Subgroup analysis by age group demonstrated a significant increase in the concentrations of CXC chemokines, between the T1DM patients and controls, among the children/adolescents $(\mathrm{SMD}=0.69$; $95 \% \mathrm{CI}: 0.13$ to 1.26 ; Table 2 ), but not among the adults. Likewise, subgroup analysis by sample type revealed a significant difference in the concentrations of CXC chemokines, between the T1DM patients and controls, when the plasma samples were used ( $\mathrm{SMD}=3.00 ; 95 \% \mathrm{CI}$ : 0.97 to 5.03; Table 2); and when the serum samples were used $(\mathrm{SMD}=0.83 ; 95 \% \mathrm{CI}$ : 0.56 to 1.11; Table 2); but this was not the case when the whole blood samples were used. Also, subgroup analysis by BMI revealed a significant difference in the concentrations of $\mathrm{CXC}$ chemokines, between the T1DM patients and controls, among the study participants with a BMI $<=23.9$ (SMD=1.06; 95\% CI: 0.69 to 1.42 ; Table 2 ), but not among the study participants with a BMI > 23.9. Similarly, subgroup analysis demonstrated a significant difference in the concentrations of CXC chemokines, between the T1DM patients and controls, when the duration of T1DM was $<60$ months $(\mathrm{SMD}=1.10 ; 95 \% \mathrm{CI}$ : 0.58 to 1.61 ; Table 2 ), but not when the duration of T1DM was $>=60$ months.

Among the 32 studies, 20 nodes involving different chemokines, between the T1DM patients and controls, were included in the network analysis. Figure $\mathbf{3 A}$ presents the network graph. Additionally, Figure 3B presents the cumulative rank probability plot. This plot shows the relative cumulative probabilities for the chemokines in the network. Therefore, the CCL5 chemokine had the highest SUCRA probability (95.8\%) and was ranked the highest in T1DM, followed by circulating CCL4, CCL3, CXCR3, CXCL1, CXCR4, CXCL8, CCL7, CCR5, CXCL10, CCL19, CXCL9, CXCL5, CCL11, CCL13, CCL2, CCR2, CXCL11 and CCL22.

\section{DISCUSSION}

To our knowledge, this is the most comprehensive systematic review of the role of chemokine systems in the pathophysiological process of T1DM. Chemokines and their receptors are expressed throughout in both the patients with T1DM and healthy subjects, under both inflammatory and 

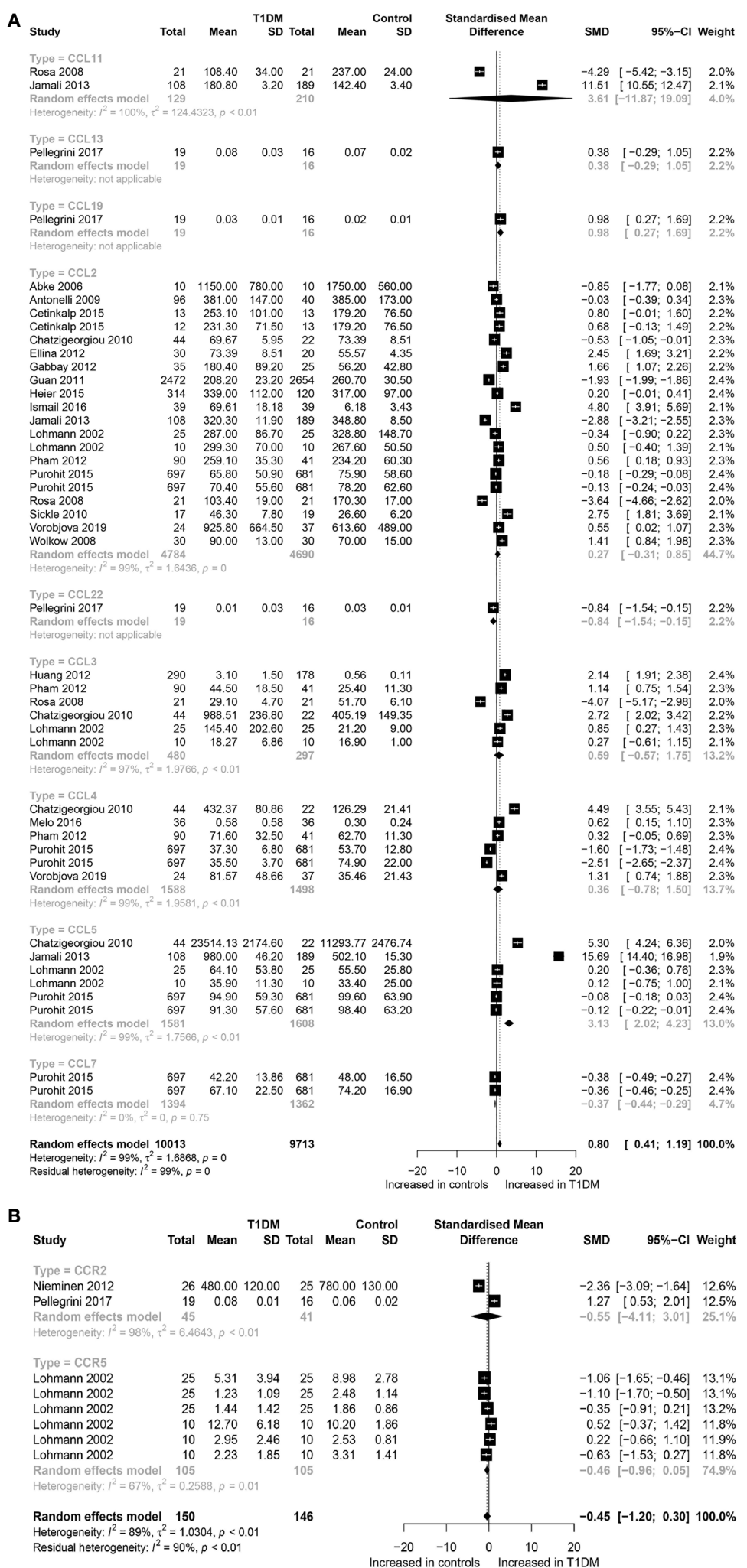

FIGURE 1 | Forest plot of CC chemokines (A) and CCR (B) between T1DM patients and controls. Study effect sizes of chemokines differences between T1DM and controls. Each data marker represents a study, and the size of the data marker is proportional to the total number of individuals in that study. The summary effect size for each chemokines is denoted by a diamond. T1DM, Type 1 diabetes mellitus; CCR, CC chemokines receptor; SMD, standardized mean difference. 


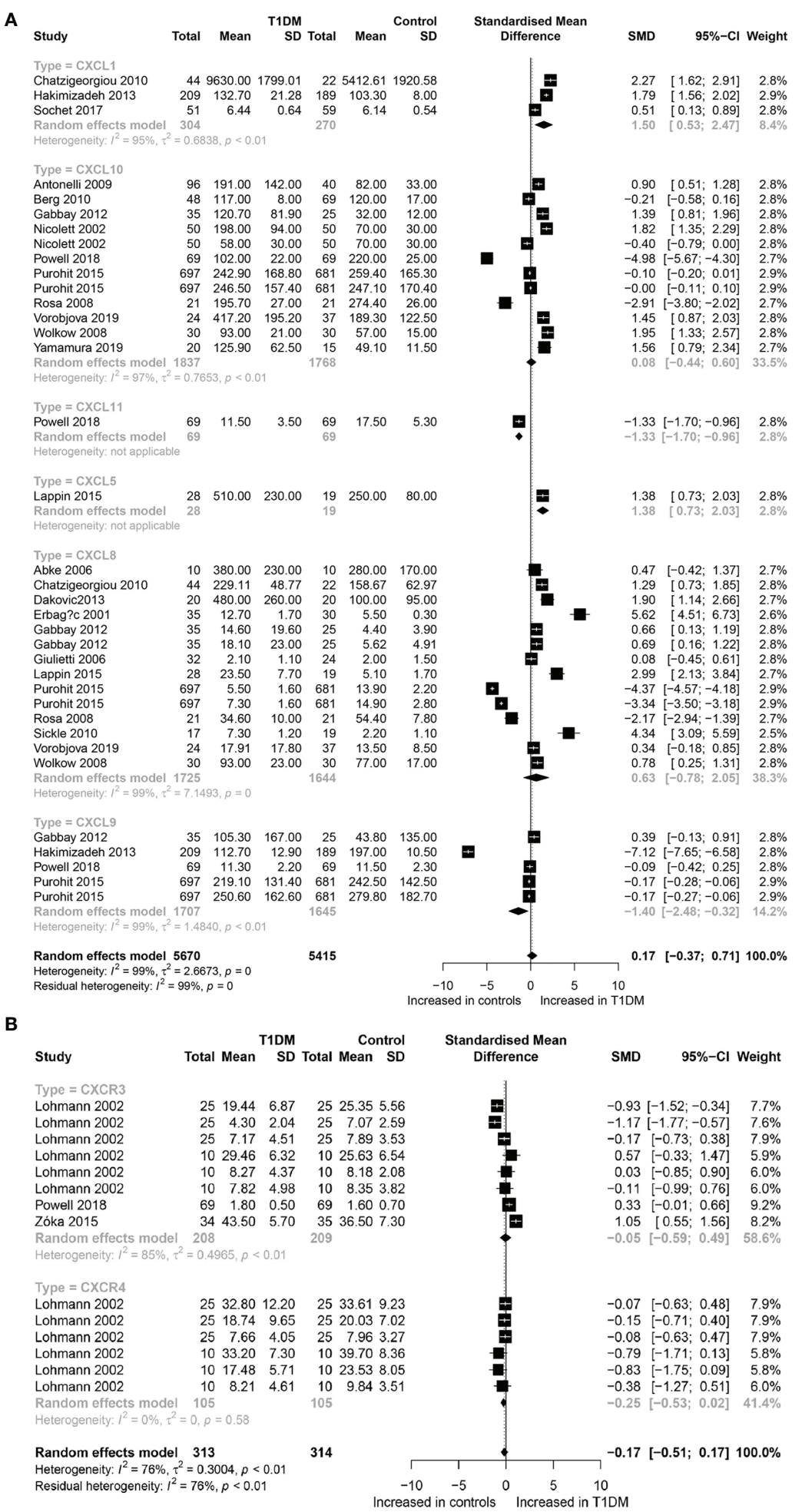

FIGURE 2 | Forest plot of CXC chemokines (A) and CXCR (B) between T1DM patients and controls. Study effect sizes of chemokines differences between T1DM and controls. Each data marker represents a study, and the size of the data marker is proportional to the total number of individuals in that study. The summary effect size for each chemokines is denoted by a diamond; T1DM, Type 1 diabetes mellitus; CXCR, CXC chemokines receptor; SMD, standardized mean difference. 
TABLE 2 | Subgroup analysis of CC and CXC chemokine between T1DM participants and controls.

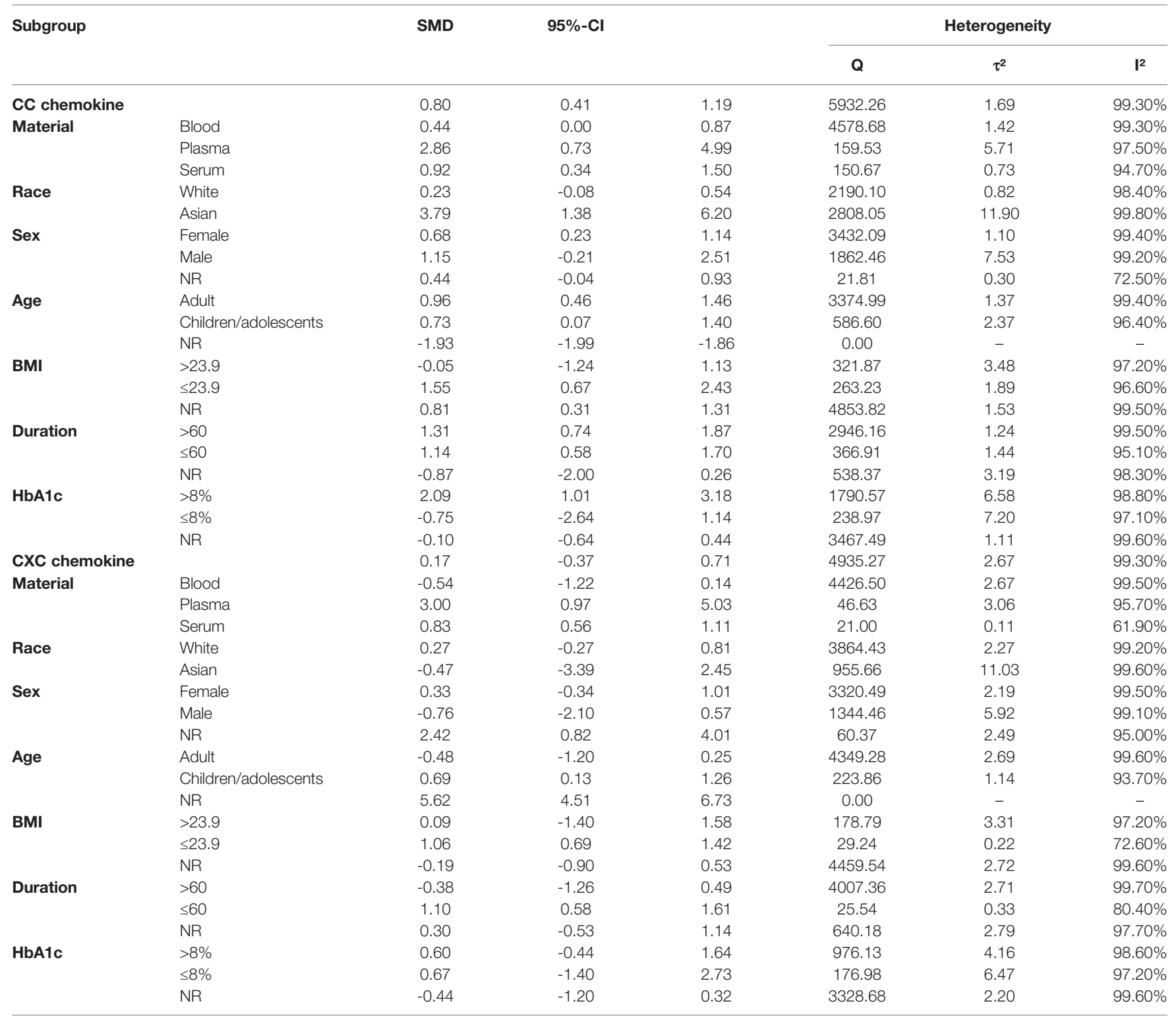

Subgroup analyses are performed to compare the concentration of chemokines and chemokines receptors between the T1DM and the controls. Heterogeneity was quantified using $l^{2}$ and its significance was tested using the Q statistics. T1DM, Type-1 diabetes mellitus, NR, not report; SMD, standardized mean difference.

physiological conditions. Our study indicates that a number of these chemokines (i.e., CCL5, CCL7, CXCL1, and CXCL9) discriminate between those with and without T1DM.

Inflammation appears to be involved in the interplay among chemokines and progression of T1DM, as this has been shown in other several pathological conditions (65-68). Moreover, recent reviews suggested that the chemokines, CXCL10, CXCL9, and CXCL11, are implicated in the pathogenesis of autoimmune diseases such as autoimmune thyroiditis, T1DM, Graves disease, Thyroid eye disease, and Addison's disease (69-72). Also, evidence indicated that CCL2 and CXCL10 chemokines, modulated by cytokines and PPAR $\gamma$ agonist, play an important role in Graves' ophthalmopathy (73). Specifically, PPAR $\gamma$ agonist activation plays an inhibitory role on CXCL10, but stimulates the release of CCL2. Moreover, a recent systematic review and metaanalysis suggested that the chemokines, CCL3, CCL4, CCL5, CCL20, CXCL8 and CXCL11, are implicated in the pathogenesis of non-alcoholic fatty liver disease, post-traumatic stress disorder, and also different types of cancers (74-77).

Furthermore, T1DM is believed to be an immunocytesmediated autoimmune disease, whose microenvironment is influenced by the chemokines system in a variety of ways. For example, pancreatic islets and peri-pancreatic adipose tissue (PAT) are exposed to early damage and start to secrete numerous pro-inflammatory chemokines. Also, the effective chemokines and their receptors can cause a variety of immune cells to enter into the pancreatic islets and PAT site, where they simulate an immune attack. Noteworthy, T1DM progression is 
A

B

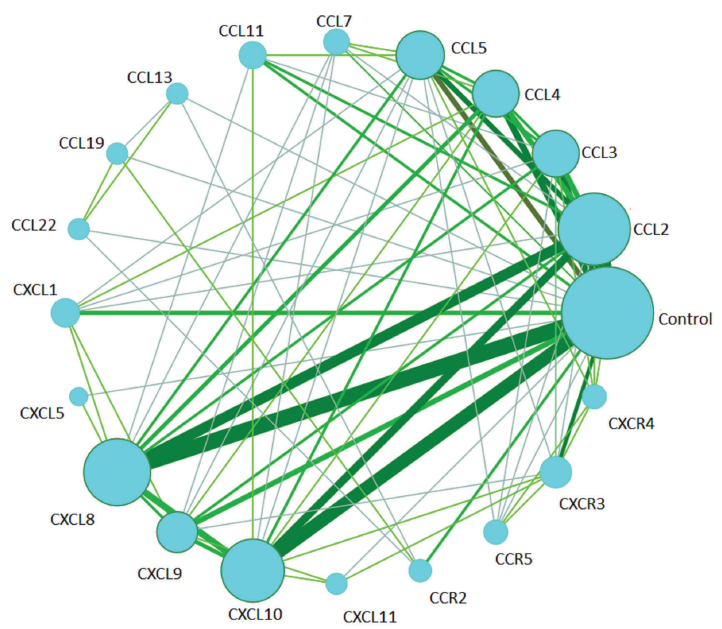

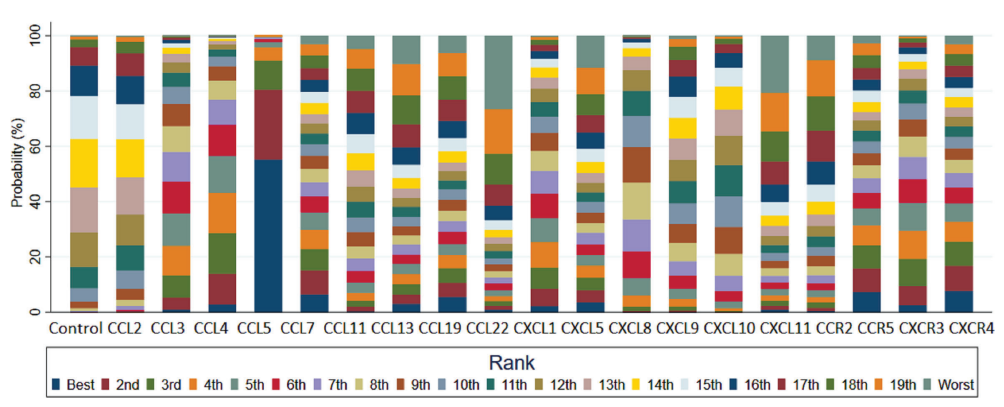

FIGURE 3 | Network meta-analysis of chemokines comparisons for T1DM (A) and rank probability of chemokines in T1DM group for response rate in the network analysis (B). The width of lines is proportional to the number of studies comparing every pair of chemokines. The size of each circle is proportional to the sample size (i.e., number of participants). (A) This plot shows the relative cumulative probabilities for each of the chemokines in the network. SUCRA values are presented in the legend. SUCRA, surface under cumulative ranking curve (B).

characterized by a massive and progressive secretion of proinflammatory chemokines caused by selectively destruction of insulin-producing $\beta$ cells in the pancreas. Therefore, due to this process, various immune cell types (i.e., neutrophils, macrophages, NK cell, dendritic cell and specifically $\mathrm{T}$ cells) are recruited in the pancreatic tissue. These immune cells further release more innate inflammatory cytokines, which contribute to the rapid increase of $\beta$ cell death. Thus, the preceding evidence support the hypothesis of a cross talk between different chemokines that are involved in the progressive auto-reactive immune response, and potentially contribute to both the initial pancreatic damage and the intense progression to overt T1DM (Figure 4). Specifically, this hypothesis is further strengthened by the evidence that, in humans, increased CCL5 was observed in the blood of newly diagnosed T1DM patients (50). These data indicated that CCL5 may be an important novel biomarker of T1DM (48). Moreover, CCL5 is identified as the dominant chemokine (in an inducible nitric oxide synthase-dependent but not NF-kappa B-dependent fashion) expressed in vivo in the islet inflammatory microenvironment of prediabetic animals and T1DM patients (78). Nevertheless, more indications toward the role of CCL5 during the pathogenesis of T1DM have been derived from cell experiments and animal models. For example, in the nonobese-diabetic (NOD) mouse, it was demonstrated that islet-specific Th1 but not helper T-cell 2 (Th2)-type cells produced CCL5 and promoted rapid induction of autoimmune diabetes (79). Another study that analyzed pancreas lysates found a massive increase in CCL5 levels at around ten weeks of age, which was found to remain high until at the age of at least 20 weeks (80). These elevated levels of CCL5 most likely reflected the degree of infiltration of pancreatic islets by autoaggressive Tcells, which are capable of producing CCL5. It was reported that CCR5 expression was detected in the islet lymphocytes and spleen of NOD mice; and it is also well known that CCL5 binds to the chemokine receptors, CCR5, which may contribute to the T1DM development (81).

Interestingly, results of another study indicated that proinflammatory cytokine produced from PATs not only significantly up-regulates CCL5 expression in islets, but also has direct cytotoxic effects on pancreatic islets. Besides, CCL5 is responsible for the recruitment of immune cells, which induces persistent inflammation in pancreases through the acquisition of Th1 and Th17 effector T cell subsets at the onset of T1DM (82). This evidence is consistent with our findings from both metaanalysis and network meta-analysis, which suggested that CCL5 may play a central role in the pathogenesis of T1DM. 


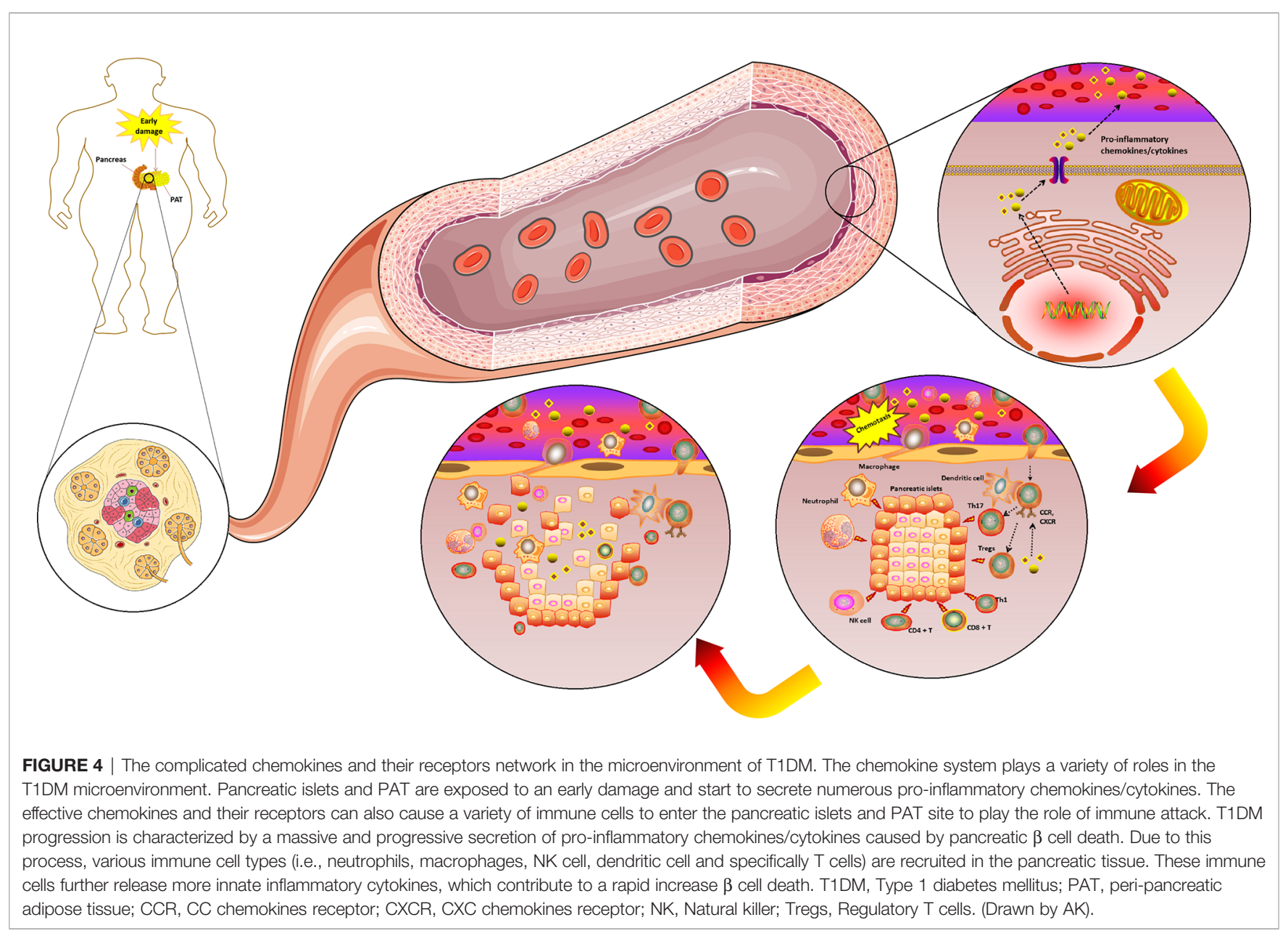

However, our results also showed that the levels of circulating CCL7 decreased in T1DM. This is not consistent with a previous animal study, which found that CCL2, CCL5 and CCL7 were significantly expressed in NOD mice with T1DM (83). This contradiction may be due to the differences between animals and humans, or lack of data from human studies. Therefore, the results of CCL7 concentrations in T1DM should be interpreted cautiously. Further investigation is warranted on how CCL7 directly contributes to T1DM progression.

We also found that measured circulating CXCL1 levels were significantly higher in the T1DM patients than in the healthy subjects. This trend was also observed in animal studies $(37,44)$. Using the microarray approach, a study found a prominent expression of CXCL1, CXCL5 and CXCL9 in the NOD mice with T1DM (83). Generally, murine $\beta$ cells can secrete large amounts of chemokines such as CXCL1; and cytokines such as IL- $1 \alpha$, and IL- 6 that can, by themselves, improve leucocyte recruitment, and hence play a role in the pathophysiology of T1DM (84). A high affinity receptor of CXCL1, designated CXCR2, is physiologically expressed on the cell surface of different leukocyte subgroups (i.e., endothelial cells, basophils, NK cells, neutrophils, monocytes, and macrophages). Thus, reactive oxygen species (ROS), environmental stresses, or inflammatory signals such as IL-1 and TNF- $\alpha$ may induce CXCL1 expression and the activation of CXCR2 pathway (85). During inflammation, different leukocyte subgroups cause extravasation from the blood vessel, and recruitment to inflamed tissue is tightly regulated by the chemokine system. Furthermore, we speculate that the CXCL1-CXCR2 pathway may be involved in neutrophil activation and increased vascular permeability, hence different leukocyte subgroups may further be activated and migrate towards the damaged tissue (86). Since CXCL1 is thought to play a crucial part in the T1DM pathogenesis, alongside different leukocyte subgroup recruitment, anti-inflammatory strategies need to be further investigated.

Additionally, prediabetes animal studies suggested that CXCL10 is one of the major chemokines expressed in vivo in the islet environment $(78,87)$. That is, in the islet of prediabetes animal, $\beta$ cells can regulate the autoimmune response by producing CXCL10, under the action of inflammatory factors such as IFN- $\gamma$ and TNF- $\alpha$. Thus, CXCL10 can induce the migration of Th1 lymphocytes into the islet and secrete more IFN- $\gamma$ and TNF- $\alpha$, then further stimulate $\beta$ cells to produce chemokines, hence initiating and perpetuating the autoimmune cascade (88). Mechanistically, another study found that in the 
pancreases of autoimmune diabetic mice, the expression of CXCL10 chemokine, which attracts plasma cell like dendritic cells (pDCs), was significantly increased, and this resulted in a significant increase in the number of $\mathrm{pDCs}$ in the islet microenvironment (89). Moreover, pDCs play a role in promoting diabetes (89). In addition, findings of a previous study suggested that blocking of CXCL10 can impede the expansion of peripheral Ag-specific $\mathrm{T}$ cells and hinder their migration to the islet microenvironment (90). Furthermore, the CXCL10 blockade aborts Ag-specific injury of $\beta$ cells in the islet microenvironment and abrogates T1DM (91). In this regard, it was shown that, after the treatment of CXCL10 DNA vaccination (pCAGGS-CXCL10), the spontaneous diabetic mice could induce the production of anti-CXCL10 $\mathrm{Ab}$ and inhibit the occurrence of spontaneous diabetes in vivo $(92,93)$. Specifically, the CXCL10 DNA vaccination resulted in the proliferation of islet $\beta$ cells in the spontaneous diabetic mice model, and helped to maintain the quality of pancreatic $\beta$ cells (93). All the above evidence indicates that the CXCL10 plays a key role in the development of T1DM in animal models. However, our study did not find any significant difference in the concentrations of CXCL10 between the T1DM and control groups. This may suggest that the role of CXCL10 in T1DM vary between species. Future studies should verify the role of CXCL10 in T1DM in larger sample sizes.

Considering the redundant nature of the chemokine system signaling, the most efficient intervention tactic should directly target the chemokine receptors. Although various approaches for blocking the chemokine receptor pathways are available, such as small molecules, peptide-derived or neutralizing antibodies, and inhibitors, they are in the preclinical stage and more randomized clinical trials are needed to prove their effectiveness in the future (94).

In vitro chemotaxis assays confirmed that lymphocytes infiltrating human islets, once stimulated by inflammatory cytokines (TNF- $\alpha$ and IFN- $\gamma$ ), are able to modulate the autoimmune response through the production of CXCL9. That is, CXCL9 can induce the migration of Th1 lymphocytes into the islet and secrete more TNF- $\alpha$ and IFN- $\gamma$, in this way initiating and perpetuating the autoimmune cascade (70). Moreover, it was shown that CXCL9 could promote the chemotaxis of activated NK cells and $\mathrm{T}$ cells through selective high affinity binding to CXCR3 (95). Interestingly, a study that evaluated the effects of genetic variability of CXCL9 and its dependence on the risk of T1DM in the German population, did not find an association of the CXCL9 polymorphisms with T1DM (96). However, our results indicated decreased levels of CXCL9 in the T1DM patients. Considering these opposing findings, our results on the association of CXCL9 with T1DM should be interpreted with caution. Further studies are needed to reveal why CXCL9 was reduced in T1DM.

The results of subgroup analysis indicated that significant differences in circulating CC chemokine concentrations, between the T1DM patients and controls, depended on type of race, or sex. This is in agreement with the findings of previous studies, which suggested that there are race and sex differences in the function of chemokine genes $(97,98)$. Therefore, we speculate that race and sex differences in the pathophysiological process of T1DM may be an important factor in stratification and individualized treatment of T1DM patients. Further, subgroup analysis showed that the circulating concentration of CC chemokines was significantly different between the T1DM patients and controls in participants with BMI $<23.9$, or HbAlc $>8 \%$. This may be due to the disorder of glucose and lipid metabolism in obese T1DM patients, which further destroys the homeostasis of the immune system and chemokines. Also, subgroup analysis revealed that materials from different sample sources significantly affected CXC chemokine concentrations in T1DM patients in that these concentrations differed significantly between patients with T1DM and controls, when plasma or serum samples were used, but this was not the case when whole blood samples were used. These results suggest that whole blood may not be a stable sample source for chemokines. Therefore, we recommend that serum or plasma samples should be used to detect CXC chemokines in future studies. Furthermore, subgroup analysis revealed that age and duration of diabetes significantly affected circulating CXC chemokine concentrations in T1DM patients. That is, unlike among adults and patients with T1DM for less than 60 months, there was a significant difference in circulating CXC chemokine concentrations between the T1DM patients and controls among children/adolescents and those with T1DM for at least 60 months. These results are consistent with the findings from age related inflammation kinetics studies, which suggested that patients gradually lose the ability to control excessive inflammatory response with the increase in age and duration of T1DM $(99,100)$. Also, when compared with healthy controls, a characteristic feature of patients with T1DM is that they have self-reactive $\mathrm{T}$ cells with a memory phenotype (13). These autoreactive memory $\mathrm{T}$ cells are likely to be long-lived and strongly responsive to antigenic stimulation with less dependence on costimulation for activation and clonal expansion, and hence may be the source of differences in circulating chemokine concentrations between the patients with T1DM and the controls $(8,13)$.

\section{Strengths and Limitations}

This study has some strengths and limitations. First, we analyzed a large number of chemokines due to the use of a comprehensive search strategy during literature search. However, some chemokines with stronger glycosaminoglycan (GAG)-binding effect have concentration levels below the detectable limit in the blood circulation. Therefore, more sensitive methods should be used to detect chemokines in circulating blood in the future. For example, future studies can use Luminex liquid phase protein chip technology and Novogene high-quality sequencing technology, to detect multiple chemokines as comprehensively as possible in a single study. Second, confounding factors such as smoking, drinking, and blood pressure, were not measured or adjusted for in the included original studies, which might have affected the stability of the chemokines concentrations. Moreover, subgroup analysis suggested that circulating samples (blood, serum, and plasma) could be potential sources of 
heterogeneity on the association between chemokines and T1DM. Future studies should consider these confounding factors and address them during data analysis. Third, the original studies did not report data related to the onset of symptoms of T1DM. Thus, we categorized the time of disease duration as $>=5$ years, or $<5$ years, a time when the pancreases of patients with T1DM have already been destroyed, and when the chemokine profile is probably quite different from that at the time of pancreatic injury. Therefore, if the purpose of future research is to analyze the potential role of chemokines and their receptors in the pathogenesis of T1DM, then the research should be conducted earlier during the onset of symptoms of the disease. However, in our study, the circulating concentrations of chemokines in the long-term course of the disease could be used as potential biomarkers. Fourth, the results of this study only describe the relationship between chemokines and T1DM status, which can provide important hypotheses for studies on causal relationships. The causal association between chemokines and pathogenesis, diagnosis and treatment of T1DM was not explored in this study due to the fact that all the original studies were case-control studies, and lacked data on the pancreas donors and onset of symptoms of T1DM. In addition, at the time this study was conducted, there was no cohort study investigating the causal association between chemokines and T1DM. Therefore, the findings of this study cannot describe any causal relationship between chemokines and T1DM. We recommend that population-based cohort studies should be conducted in future to determine the role of chemokines in the pathogenesis of T1DM, or the possible causal/dose-response relationship between T1DM and chemokines, and these studies should be performed on samples obtained not only from circulating samples but also pancreas donors. Further, our study did not find an association between CXCL10 and T1DM, although previous studies found significant associations between CXCL10 and diabetes in animal models. Finally, despite some limitations, the findings of our study have helped to clarify the intricacies of previous results, and suggest that chemokines have a significant correlation with the state of T1DM; hence can most likely serve as biomarkers for T1DM.

\section{CONCLUSIONS}

The results of this study suggest that circulating CCL5 and CXCL1 are altered in T1DM patients. In addition, circulating

\section{REFERENCES}

1. Al Khalifah RA, Alnhdi A, Alghar H, Alanazi M, Florez ID. The Effect of Adding Metformin to Insulin Therapy for Type 1 Diabetes Mellitus Children: A Systematic Review and Meta-Analysis. Pediatr Diabetes (2017) 18(7):664-73. doi: 10.1111 /pedi.12493

2. Chen YL, Qiao YC, Pan YH, Xu Y, Huang YC, Wang YH, et al. Correlation Between Serum Interleukin-6 Level and Type 1 Diabetes Mellitus: A Systematic Review and Meta-Analysis. Cytokine (2017) 94:14-20. doi: 10.1016/j.cyto.2017.01.002

3. Chang TT, Chen JW. Emerging Role of Chemokine CC Motif Ligand 4 Related Mechanisms in Diabetes Mellitus and Cardiovascular Disease: Friends or Foes? Cardiovasc Diabetol (2016) 15(1):117. doi: 10.1186/s12933-016-0439-9
CCL7, CXCL9 and CXCL10 may be underlying biomarkers for T1DM. Future studies are needed to ascertain causal associations between chemokines and T1DM.

\section{DATA AVAILABILITY STATEMENT}

The raw data supporting the conclusions of this article will be made available by the authors, without undue reservation.

\section{AUTHOR CONTRIBUTIONS}

$\mathrm{XP}$ and $\mathrm{AL}$ contributed to the study design, while XP and $\mathrm{AK}$ contributed to the data collection. Statistical analyses and interpretation of results were performed by $\mathrm{AL}, \mathrm{XT}$, and $\mathrm{AK}$, whereas XP, XT, SK, HL, AL, and SW drafted the manuscript and edited the language. All the authors participated in the critical revisions, and approved the final version of the manuscript.

\section{FUNDING}

The research is financially supported by Hunan Provincial Key Laboratory of Clinical Epidemiology and the Hunan Provincial Key Research and Development Program (2018SK2065), China.

\section{ACKNOWLEDGMENTS}

We are grateful to Central South University Library for their assistance during the literature search. Furthermore, we sincerely appreciate the hard work from the distinguished editors and reviewers.

\section{SUPPLEMENTARY MATERIAL}

The Supplementary Material for this article can be found online at: https://www.frontiersin.org/articles/10.3389/fimmu.2021. 690082/full\#supplementary-material

4. Magnus MC, Olsen SF, Granström C, Joner G, Skrivarhaug T, Svensson J, et al. Infant Growth and Risk of Childhood-Onset Type 1 Diabetes in Children From 2 Scandinavian Birth Cohorts. JAMA Pediatr (2015) 169(12):e153759. doi: 10.1001/jamapediatrics.2015.3759

5. Musso G, Gambino R, Cassader M, Paschetta E. Efficacy and Safety of Dual SGLT 1/2 Inhibitor Sotagliflozin in Type 1 Diabetes: Meta-Analysis of Randomised Controlled Trials. BMJ (2019) 365:11328. doi: 10.1136/bmj.11328

6. Adverse Events and Their Association With Treatment Regimens in the Diabetes Control and Complications Trial. Diabetes Care (1995) 18 (11):1415-27. doi: 10.2337/diacare.18.11.1415

7. Kilpatrick ES, Rigby AS, Atkin SL. Insulin Resistance, the Metabolic Syndrome, and Complication Risk in Type 1 Diabetes: "Double Diabetes" in the Diabetes 
Control and Complications Trial. Diabetes Care (2007) 30(3):707-12. doi: $10.2337 / \mathrm{dc} 06-1982$

8. Chatzigeorgiou A, Harokopos V, Mylona-Karagianni C, Tsouvalas E, Aidinis V, Kamper EF. The Pattern of Inflammatory/Anti-Inflammatory Cytokines and Chemokines in Type 1 Diabetic Patients Over Time. Ann Med (2010) 42 (6):426-38. doi: 10.3109/07853890.2010.495951

9. Citro A, Cantarelli E, Piemonti L. The CXCR1/2 Pathway: Involvement in Diabetes Pathophysiology and Potential Target for T1D Interventions. Curr Diabetes Rep (2015) 15(10):68. doi: 10.1007/s11892-015-0638-x

10. Antonelli A, Ferrari SM, Corrado A, Ferrannini E, Fallahi P. CXCR3, CXCL10 and Type 1 Diabetes. Cytokine Growth Factor Rev (2014) 25(1):57-65. doi: 10.1016/j.cytogfr.2014.01.006

11. Christen U. Chemokines as Drug Targets in Type 1 Diabetes. Endocr Metab Immune Disord Drug Targets (2007) 7(1):7-12. doi: 10.2174/187153007780059405

12. Lo J, Clare-Salzler MJ. Dendritic Cell Subsets and Type I Diabetes: Focus Upon DC-Based Therapy. Autoimmun Rev (2006) 5(6):419-23. doi: 10.1016/ j.autrev.2005.12.001

13. Ehlers MR, Rigby MR. Targeting Memory T Cells in Type 1 Diabetes. Curr Diabetes Rep (2015) 15(11):84. doi: 10.1007/s11892-015-0659-5

14. Chang TT, Chen JW. Emerging Role of Chemokine CC Motif Ligand 4 Related Mechanisms in Diabetes Mellitus and Cardiovascular Disease: Friends or Foes? Cardiovasc Diabetol (2016) 15(1):117. doi: 10.1186/s12933-0160439-9

15. Vidakovic M, Grdovic N, Dinic S, Mihailovic M, Uskokovic A, Jovanovic JA. The Importance of the CXCL12/CXCR4 Axis in Therapeutic Approaches to Diabetes Mellitus Attenuation. Front Immunol (2015) 6:403. doi: 10.3389/ fimmu.2015.00403

16. Sánchez-Martín L, Sánchez-Mateos P, Cabañas C. CXCR7 Impact on CXCL12 Biology and Disease. Trends Mol Med (2013) 19(1):12-22. doi: 10.1016/ j.molmed.2012.10.004

17. Moher D, Liberati A, Tetzlaff J, Altman DG. Preferred Reporting Items for Systematic Reviews and Meta-Analyses: The PRISMA Statement. BMJ (2009) 339:b2535. doi: 10.1136/bmj.b2535

18. Stang A. Critical Evaluation of the Newcastle-Ottawa Scale for the Assessment of the Quality of Nonrandomized Studies in Meta-Analyses. Eur J Epidemiol (2010) 25(9):603-5. doi: 10.1007/s10654-010-9491-z

19. Pan X, Wang Z, Wu X, Wen SW, Liu A. Salivary Cortisol in Post-Traumatic Stress Disorder: A Systematic Review and Meta-Analysis. BMC Psychiatry (2018) 18(1):324. doi: 10.1186/s12888-018-1910-9

20. Pan X, Kaminga AC, Wen SW, Wu X, Acheampong K, Liu A. Dopamine and Dopamine Receptors in Alzheimer's Disease: A Systematic Review and Network Meta-Analysis. Front Aging Neurosci (2019) 11:175. doi: 10.3389/ fnagi.2019.00175

21. Pan X, Wen SW, Kaminga AC, Liu A. Gut Metabolites and Inflammation Factors in Non-Alcoholic Fatty Liver Disease: A Systematic Review and MetaAnalysis. Sci Rep (2020) 10(1):8848. doi: 10.1038/s41598-020-65051-8

22. Higgins JP, Thompson SG, Deeks JJ, Altman DG. Measuring Inconsistency in Meta-Analyses. BMJ (2003) 327(7414):557-60. doi: 10.1136/bmj.327.7414.557

23. Pan X, Kaminga AC, Chen J, Luo M, Luo J. Fetuin-A and Fetuin-B in NonAlcoholic Fatty Liver Disease: A Meta-Analysis and Meta-Regression. Int J Environ Res Public Health (2020) 17(8):2735. doi: 10.3390/ijerph17082735

24. Cohen J. Statistical Power Analysis for the Behavioral Science. Technometrics (1988) 31(4):499-500.

25. Michael H, Thornton S, Xie M, Tian L. Exact Inference on the Random-Effects Model for Meta-Analyses With Few Studies. Biometrics (2019) 75(2):485-93. doi: 10.1111/biom.12998

26. Riley RD, Higgins JPT, Deeks JJ. Interpretation of Random Effects MetaAnalyses. BMJ Br Med J (2011) 342:d549.

27. Higgins JP. Quantifying Heterogeneity in a Meta-Analysis. Stat Med (2002) 11 (21):1539-58.

28. DerSimonian R, Laird N. Meta-Analysis in Clinical Trials Revisited. Contemp Clin Trials (2015) 45(Pt A):139-45. doi: 10.1016/j.cct.2015.09.002

29. Pan X, Wu X, Kaminga AC, Wen SW, Liu A. Dehydroepiandrosterone and Dehydroepiandrosterone Sulfate in Alzheimer's Disease: A Systematic Review and Meta-Analysis. Front Aging Neurosci (2019) 11:61. doi: 10.3389/ fnagi.2019.00061

30. Egger M, Davey Smith G, Schneider M, Minder C. Bias in Meta-Analysis Detected by a Simple, Graphical Test. BMJ (1997) 315(7109):629-34.
31. White IR, Barrett JK, Jackson D, Higgins JP. Consistency and Inconsistency in Network Meta-Analysis: Model Estimation Using Multivariate MetaRegression. Res Synth Methods (2012) 3(2):111-25. doi: 10.1002/jrsm.1045

32. Salanti G, Ades AE, Ioannidis JP. Graphical Methods and Numerical Summaries for Presenting Results From Multiple-Treatment Meta-Analysis: An Overview and Tutorial. J Clin Epidemiol (2011) 64(2):163-71. doi: 10.1016/j.jclinepi.2010.03.016

33. Abke S, Neumeier M, Weigert J, Wehrwein G, Eggenhofer E, Schäffler A, et al. Adiponectin-Induced Secretion of Interleukin-6 (IL-6), Monocyte Chemotactic Protein-1 (MCP-1, CCL2) and Interleukin-8 (IL-8, CXCL8) Is Impaired in Monocytes From Pateints With Type I Diabetes. Cardiovasc Diabetol (2006) 5:17. doi: 10.1186/1475-2840-5-17

34. Antonelli A, Fallahi P, Ferrari SM, Pupilli C, d'Annunzio G, Lorini R, et al. Serum Th1 (CXCL10) and Th2 (CCL2) Chemokine Levels in Children With Newly Diagnosed Type 1 Diabetes: A Longitudinal Study. Diabetic Med (2008) 25(11):1349-53. doi: 10.1111/j.1464-5491.2008.02577.x

35. Berg AK, Tuvemo T, Frisk G. Enterovirus Markers and Serum CXCL10 in Children With Type 1 Diabetes. J Med Virol (2010) 82(9):1594-9. doi: $10.1002 / j m v .21868$

36. Cetinkalp S, Felekoglu C, Karadeniz M, Boyacioglu H, Delen Y, Yildirim E, et al. Comparison of the Effects of Intensive Insulin Treatment Modalities on Cardiovascular Biomarkers in Type 1 Diabetes Mellitus. Diabetes Metab Syndr: Clin Res Rev (2015) 9(3):157-62. doi: 10.1016/j.dsx.2015.04.011

37. Chatzigeorgiou A, Harokopos V, Mylona-Karagianni C, Tsouvalas E, Aidinis V, Kamper E. The Pattern of Inflammatory/Anti-Inflammatory Cytokines and Chemokines in Type 1 Diabetic Patients Over Time. Ann Med (2010) 42 (6):426-38. doi: 10.3109/07853890.2010.495951

38. Dakovic D, Colic M, Cakic S, Mileusnic I, Hajdukovic Z, Stamatovic N. Salivary Interleukin-8 Levels in Children Suffering From Type 1 Diabetes Mellitus. J Clin Pediatr Dent (2013) 37(4):377-80. doi: 10.17796/ jcpd.37.4.1135531h4542gj66

39. Ellina O, Chatzigeorgiou A, Kouyanou S, Lymberi M, Mylona-Karagianni C, Tsouvalas E, et al. Extracellular Matrix-Associated (GAGs, CTGF), Angiogenic (VEGF) and Inflammatory Factors (MCP-1, CD40, IFNGamma) in Type 1 Diabetes Mellitus Nephropathy. Clin Chem Lab Med (2012) 50(1):167-74. doi: 10.1515/cclm.2011.881

40. Erbağci AB, Tarakçioğlu M, Coşkun Y, Sivasli E, Sibel Namiduru E. Mediators of Inflammation in Children With Type I Diabetes Mellitus: Cytokines in Type I Diabetic Children. Clin Biochem (2001) 34(8):645-50. doi: 10.1016/ s0009-9120(01)00275-2

41. Gabbay MA, Sato MN, Duarte AJ, Dib SA. Serum Titres of Anti-Glutamic Acid Decarboxylase-65 and Anti-IA-2 Autoantibodies are Associated With Different Immunoregulatory Milieu in Newly Diagnosed Type 1 Diabetes Patients. Clin Exp Immunol (2012) 168(1):60-7. doi: 10.1111/j.1365-2249.2011.04538.x

42. Giulietti A, van Etten E, Overbergh L, Stoffels K, Bouillon R, Mathieu C. Monocytes From Type 2 Diabetic Patients Have a Pro-Inflammatory Profile. 1,25-Dihydroxyvitamin D(3) Works as Anti-Inflammatory. Diabetes Res Clin Pract (2007) 77(1):47-57. doi: 10.1016/j.diabres.2006.10.007

43. Guan R, Purohit S, Wang H, Bode B, Reed JC, Steed RD, et al. Chemokine (C-C Motif) Ligand 2 (CCL2) in Sera of Patients With Type 1 Diabetes and Diabetic Complications. PLoS One (2011) 6(4):e17822. doi: 10.1371/journal. pone. 0017822

44. Hakimizadeh E, Shamsizadeh A, Nazari M, Arababadi MK, Rezaeian M, Vazirinejad R, et al. Increased Circulating Levels of CXC Chemokines is Correlated With Duration and Complications of the Disease in Type-1 Diabetes: A Study on Iranian Diabetic Patients. Clin Lab (2013) 59(56):531-7. doi: 10.7754/Clin.Lab.2012.120518

45. Heier M, Margeirsdottir HD, Brunborg C, Hanssen KF, Dahl-Jorgensen K, Seljeflot I. Inflammation in Childhood Type 1 Diabetes; Influence of Glycemic Control. Atherosclerosis (2015) 238(1):33-7. doi: 10.1016/j.atherosclerosis. 2014.11.018

46. Huang G, Mo X, Li M, Xiang Y, Li X, Luo S, et al. Autoantibodies to CCL3 are of Low Sensitivity and Specificity for the Diagnosis of Type 1 Diabetes. Acta Diabetol (2012) 49(5):395-9. doi: 10.1007/s00592-012-0380-7

47. Ismail NA, Abd El Baky AN, Ragab S, Hamed M, Hashish MA, Shehata A. Monocyte Chemoattractant Protein 1 and Macrophage Migration Inhibitory Factor in Children With Type 1 Diabetes. J Pediatr Endocrinol Metab (2016) 29(6):641-5. doi: 10.1515/jpem-2015-0340 
48. Jamali Z, Nazari M, Khoramdelazad H, Hakimizadeh E, Mahmoodi M, Karimabad MN, et al. Expression of CC Chemokines CCL2, CCL5, and CCL11 Is Associated With Duration of Disease and Complications in Type-1 Diabetes: A Study on Iranian Diabetic Patients. Clin Lab (2013) 59(9-10):9931001. doi: 10.7754/Clin.Lab.2012.120810

49. Lappin DF, Robertson D, Hodge P, Treagus D, Awang RA, Ramage G, et al. The Influence of Glycated Hemoglobin on the Cross Susceptibility Between Type 1 Diabetes Mellitus and Periodontal Disease. J Periodontol (2015) 86 (11):1249-59. doi: 10.1902/jop.2015.150149

50. Lohmann T, Laue S, Nietzschmann U, Kapellen TM, Lehmann I, Schroeder S, et al. Reduced Expression of Th1-Associated Chemokine Receptors on Peripheral Blood Lymphocytes at Diagnosis of Type 1 Diabetes. Diabetes (2002) 51(8):2474-80. doi: 10.2337/diabetes.51.8.2474

51. De Melo EN, Deda L, Har R, Reich HN, Scholey JW, Daneman D, et al. The Urinary Inflammatory Profile in Gluten Free Diet-Adherent Adolescents With Type 1 Diabetes and Celiac Disease. J Diabetes Complications (2016) 30(2):295-9. doi: 10.1016/j.jdiacomp.2015.11.020

52. Nicoletti F, Conget I, Di Mauro M, Di Marco R, Mazzarino M, Bendtzen K, et al. Serum Concentrations of the Interferon- $\gamma$-Inducible Chemokine IP-10/ CXCL10 Are Augmented in Both Newly Diagnosed Type I Diabetes Mellitus Patients and Subjects at Risk of Developing the Disease. Diabetologia (2002) 45(8):1107-10. doi: 10.1007/s00125-002-0879-5

53. Nieminen JK, Vakkila J, Salo HM, Ekström N, Härkönen T, Ilonen J, et al. Altered Phenotype of Peripheral Blood Dendritic Cells in Pediatric Type 1 Diabetes. Diabetes Care (2012) 35(11):2303-10. doi: 10.2337/dc11-2460

54. Pellegrini S, Sordi V, Bolla AM, Saita D, Ferrarese R, Canducci F, et al. Duodenal Mucosa of Patients With Type 1 Diabetes Shows Distinctive Inflammatory Profile and Microbiota. J Clin Endocrinol Metab (2017) 102 (5):1468-77. doi: 10.1210/jc.2016-3222

55. Pham MN, Hawa MI, Roden M, Schernthaner G, Pozzilli P, Buzzetti R, et al. Increased Serum Concentrations of Adhesion Molecules But Not of Chemokines in Patients With Type2 Diabetes Compared With Patients With Typel Diabetes and Latent Autoimmune Diabetes in Adult Age: Action Lada5. Diabetic Med (2012) 29(4):470-8. doi: 10.1111/j.14645491.2011.03546.x

56. Powell WE, Hanna SJ, Hocter CN, Robinson E, Davies J, Dunseath GJ, et al. Loss of CXCR3 Expression on Memory B Cells in Individuals With LongStanding Type 1 Diabetes. Diabetologia (2018) 61(8):1794-803. doi: 10.1007/ s00125-018-4651-x

57. Purohit S, Sharma A, Hopkins D, Steed L, Bode B, Anderson SW, et al. LargeScale Discovery and Validation Studies Demonstrate Significant Reductions in Circulating Levels of IL8, IL-1ra, MCP-1, and MIP- $1 \beta$ in Patients With Type 1 Diabetes. J Clin Endocrinol Metab (2015) 100(9):E1179-87. doi: 10.1210/ JC.2015-1388

58. Rosa JS, Oliver SR, Mitsuhashi M, Flores RL, Pontello AM, Zaldivar FP, et al. Altered Kinetics of Interleukin-6 and Other Inflammatory Mediators During Exercise in Children With Type 1 Diabetes. J Investig Med (2008) 56(4):70113. doi: $10.2310 /$ JIM.0b013e31816c0fba

59. Van Sickle BJ, Simmons J, Hall R, Raines M, Ness K, Spagnoli A. Increased Circulating IL-8 Is Associated With Reduced IGF-1 and Related to Poor Metabolic Control in Adolescents With Type 1 Diabetes Mellitus. Cytokine (2009) 48(3):290-4. doi: 10.1016/j.cyto.2009.08.011

60. Sochett E, Noone D, Grattan M, Slorach C, Moineddin R, Elia Y, et al. Relationship Between Serum Inflammatory Markers and Vascular Function in a Cohort of Adolescents With Type 1 Diabetes. Cytokine (2017) 99:233-9. doi: 10.1016/j.cyto.2017.07.013

61. Vorobjova T, Tagoma A, Oras A, Alnek K, Kisand K, Talja I, et al. Celiac Disease in Children, Particularly With Accompanying Type 1 Diabetes, Is Characterized by Substantial Changes in the Blood Cytokine Balance, Which May Reflect Inflammatory Processes in the Small Intestinal Mucosa. J Immunol Res (2019) 2019:6179243. doi: 10.1155/2019/6179243

62. Wolkow PP, Niewczas MA, Perkins B, Ficociello LH, Lipinski B, Warram JH, et al. Association of Urinary Inflammatory Markers and Renal Decline in Microalbuminuric Type 1 Diabetics. J Am Soc Nephrol (2008) 19(4):789-97. doi: 10.1681/ASN.2007050556

63. Yamamura S, Fukui T, Mori Y, Hayashi T, Yamamoto T, Ohara M, et al. Circulating Anti-Glutamic Acid Decarboxylase-65 Antibody Titers are Positively Associated With the Capacity of Insulin Secretion in Acute-Onset
Type 1 Diabetes With Short Duration in a Japanese Population.J Diabetes Investig (2019) 10(6):1480-9. doi: 10.1111/jdi.13052

64. Zoka A, Barna G, Hadarits O, Al-Aissa Z, Wichmann B, Muzes G, et al. Altered Crosstalk in the Dipeptidyl Peptidase-4-Incretin-Immune System in Type 1 Diabetes: A Hypothesis Generating Pilot Study. Hum Immunol (2015) 76(9):667-72. doi: 10.1016/j.humimm.2015.09.018

65. Antonelli A, Ferri C, Ferrari SM, Frascerra S, Ruffilli I, Caponi L, et al. High Levels of Circulating Chemokine (C-X-C Motif) Ligand 11 are Associated With Euthyroid or Subclinically Hypothyroid Autoimmune Thyroiditis and With Chemokine (C-X-C Motif) Ligand 10. J Interf Cytokine Res (2012) 32 (2):74-80. doi: 10.1089/jir.2011.0051

66. Antonelli A, Ferrari SM, Frascerra S, Di Domenicantonio A, Nicolini A, Ferrari P, et al. Increase of Circulating CXCL9 and CXCL11 Associated With Euthyroid or Subclinically Hypothyroid Autoimmune Thyroiditis. J Clin Endocrinol Metab (2011) 96(6):1859-63. doi: 10.1210/jc.2010-2905

67. Antonelli A, Ferrari SM, Frascerra S, Ruffilli I, Gelmini S, Minuto M, et al. Peroxisome Proliferator-Activated Receptor- $\alpha$ Agonists Modulate CXCL9 and CXCL11 Chemokines in Graves' Ophthalmopathy Fibroblasts and Preadipocytes. Mol Cell Endocrinol (2012) 349(2):255-61. doi: 10.1016/ j.mce.2011.11.001

68. Antonelli A, Ferrari SM, Corrado A, Ferrannini E, Fallahi P. Increase of Interferon- $\gamma$ Inducible CXCL9 and CXCL11 Serum Levels in Patients With Active Graves' Disease and Modulation by Methimazole Therapy. Thyroid (2013) 23(11):1461-9. doi: 10.1089/thy.2012.0485

69. Fallahi P, Ferrari SM, Ragusa F, Ruffilli I, Elia G, Paparo SR, et al. Th1 Chemokines in Autoimmune Endocrine Disorders. J Clin Endocrinol Metab (2020) 105(4):dgz289. doi: 10.1210/clinem/dgz289

70. Antonelli A, Ferrari SM, Giuggioli D, Ferrannini E, Ferri C, Fallahi P. Chemokine (C-X-C Motif) Ligand (CXCL) 10 in Autoimmune Diseases. Autoimmun Rev (2014) 13(3):272-80. doi: 10.1016/j.autrev.2013.10.010

71. Fallahi P, Ferrari SM, Corrado A, Giuggioli D, Ferri C, Antonelli A. Targeting Chemokine (C-X-C Motif) Receptor 3 in Thyroid Autoimmunity. Recent Pat Endocr Metab Immune Drug Discov (2014) 8(2):95-101. doi: 10.2174/ 1872214808666140623114315

72. Fallahi P, Ferrari SM, Elia G, Nasini F, Colaci M, Giuggioli D, et al. Novel Therapies for Thyroid Autoimmune Diseases. Expert Rev Clin Pharmacol (2016) 9(6):853-61. doi: 10.1586/17512433.2016.1157468

73. Antonelli A, Ferrari SM, Corrado A, Franceschini SS, Gelmini S, Ferrannini E, et al. Extra-Ocular Muscle Cells From Patients With Graves' Ophthalmopathy Secrete $\alpha$ (CXCL10) and $\beta$ (CCL2) Chemokines Under the Influence of Cytokines That Are Modulated by PPAR $\gamma$. Autoimmun Rev (2014) 13 (11):1160-6. doi: 10.1016/j.autrev.2014.08.025

74. Pan X, Kaminga AC, Wu Wen S, Liu A. Chemokines in Post-Traumatic Stress Disorder: A Network Meta-Analysis. Brain Behav Immun (2020) 92:115-26. doi: 10.1016/j.bbi.2020.11.033

75. Pan X, Kaminga AC, Wen SW, Liu A. Chemokines in Hepatocellular Carcinoma: A Meta-Analysis. Carcinogenesis (2020) 41(12):1682-94. doi: 10.1093/carcin/bgaa106

76. Bhat AA, Nisar S, Maacha S, Carneiro-Lobo TC, Akhtar S, Siveen KS, et al. Cytokine-Chemokine Network Driven Metastasis in Esophageal Cancer; Promising Avenue for Targeted Therapy. Mol Cancer (2021) 20(1):2. doi: $10.1186 / \mathrm{s} 12943-020-01294-3$

77. Pan X, Chiwanda Kaminga A, Liu A, Wen SW, Chen J, Luo J. Chemokines in Non-Alcoholic Fatty Liver Disease: A Systematic Review and Network Meta-Analysis. Front Immunol (2020) 11:1802. doi: 10.3389/fimmu. 2020.01802

78. Sarkar SA, Lee CE, Victorino F, Nguyen TT, Walters JA, Burrack A, et al. Expression and Regulation of Chemokines in Murine and Human Type 1 Diabetes. Diabetes (2012) 61(2):436-46. doi: 10.2337/db11-0853

79. Bradley LM, Asensio VC, Schioetz LK, Harbertson J, Krahl T, Patstone G, et al. Islet-Specific Th1, But Not Th2, Cells Secrete Multiple Chemokines and Promote Rapid Induction of Autoimmune Diabetes. J Immunol (1999) 162 (5):2511-20.

80. Bouma G, Coppens JM, Mourits S, Nikolic T, Sozzani S, Drexhage HA, et al. Evidence for an Enhanced Adhesion of DC to Fibronectin and a Role of CCL19 and CCL21 in the Accumulation of DC Around the Pre-Diabetic Islets in NOD Mice. Eur J Immunol (2005) 35(8):2386-96. doi: 10.1002/ eji.200526251 
81. Carvalho-Pinto C, García MI, Gómez L, Ballesteros A, Zaballos A, Flores JM, et al. Leukocyte Attraction Through the CCR5 Receptor Controls Progress From Insulitis to Diabetes in non-Obese Diabetic Mice. Eur J Immunol (2004) 34(2):548-57. doi: 10.1002/eji.200324285

82. Shao L, Feng B, Zhang Y, Zhou H, Ji W, Min W. The Role of Adipose-Derived Inflammatory Cytokines in Type 1 Diabetes. Adipocyte (2016) 5(3):270-4. doi: 10.1080/21623945.2016.1162358

83. Matos M, Park R, Mathis D, Benoist C. Progression to Islet Destruction in a Cyclophosphamide-Induced Transgenic Model: A Microarray Overview. Diabetes (2004) 53(9):2310-21. doi: 10.2337/diabetes.53.9.2310

84. Melzi R, Mercalli A, Sordi V, Cantarelli E, Nano R, Maffi P, et al. Role of CCL2/MCP-1 in Islet Transplantation. Cell Transplant (2010) 19(8):1031-46. doi: 10.3727/096368910x514639

85. Zaslaver A, Feniger-Barish R, Ben-Baruch A. Actin Filaments are Involved in the Regulation of Trafficking of Two Closely Related Chemokine Receptors, CXCR1 and CXCR2. J Immunol (2001) 166(2):1272-84. doi: 10.4049/ jimmunol.166.2.1272

86. Pruenster M, Mudde L, Bombosi P, Dimitrova S, Zsak M, Middleton J, et al. The Duffy Antigen Receptor for Chemokines Transports Chemokines and Supports Their Promigratory Activity. Nat Immunol (2009) 10(1):101-8. doi: $10.1038 /$ ni.1675

87. Nigi L, Brusco N, Grieco GE, Licata G, Krogvold L, Marselli L, et al. Pancreatic Alpha-Cells Contribute Together With Beta-Cells to CXCL10 Expression in Type 1 Diabetes. Front Endocrinol (Lausanne) (2020) 11:630. doi: 10.3389/ fendo.2020.00630

88. Antonelli A, Ferrari SM, Corrado A, Ferrannini E, Fallahi P. CXCR3, CXCL10 and Type 1 Diabetes. Cytokine Growth Factor Rev (2014) 25(1):57-65. doi: 10.1016/j.cytogfr.2014.01.006

89. Welzen-Coppens JM, van Helden-Meeuwsen CG, Leenen PJ, Drexhage HA, Versnel MA. The Kinetics of Plasmacytoid Dendritic Cell Accumulation in the Pancreas of the NOD Mouse During the Early Phases of Insulitis. PLoS One (2013) 8(1):e55071. doi: 10.1371/journal.pone.0055071

90. Christen U, McGavern DB, Luster AD, von Herrath MG, Oldstone MB. Among CXCR3 Chemokines, IFN-Gamma-Inducible Protein of $10 \mathrm{kDa}$ (CXC Chemokine Ligand (CXCL) 10) But Not Monokine Induced by IFN-Gamma (CXCL9) Imprints a Pattern for the Subsequent Development of Autoimmune Disease. J Immunol (2003) 171(12):6838-45. doi: 10.4049/jimmunol. 171.12.6838

91. Christen U, Kimmel R. Chemokines as Drivers of the Autoimmune Destruction in Type 1 Diabetes: Opportunity for Therapeutic Intervention in Consideration of an Optimal Treatment Schedule. Front Endocrinol (Lausanne) (2020) 11:591083. doi: 10.3389/fendo.2020.591083

92. Shigihara T, Shimada A, Oikawa Y, Yoneyama H, Kanazawa Y, Okubo Y, et al. CXCL10 DNA Vaccination Prevents Spontaneous Diabetes Through Enhanced Beta Cell Proliferation in NOD Mice. J Immunol (2005) 175 (12):8401-8. doi: 10.4049/jimmunol.175.12.8401

93. Morimoto J, Yoneyama H, Shimada A, Shigihara T, Yamada S, Oikawa Y, et al. CXC Chemokine Ligand 10 Neutralization Suppresses the Occurrence of
Diabetes in Nonobese Diabetic Mice Through Enhanced Beta Cell Proliferation Without Affecting Insulitis. I Immunol (2004) 173(11):701724. doi: 10.4049/jimmunol.173.11.7017

94. Citro A, Cantarelli E, Piemonti L. The CXCR1/2 Pathway: Involvement in Diabetes Pathophysiology and Potential Target for T1D Interventions. Curr Diabetes Rep (2015) 15(10):68. doi: 10.1007/s11892-015-0638-x

95. Cole KE, Strick CA, Paradis TJ, Ogborne KT, Loetscher M, Gladue RP, et al. Interferon-Inducible T Cell Alpha Chemoattractant (I-TAC): A Novel nonELR CXC Chemokine With Potent Activity on Activated T Cells Through Selective High Affinity Binding to CXCR3. J Exp Med (1998) 187(12):2009-21. doi: 10.1084/jem.187.12.2009

96. Brück P, Bartsch W, Penna-Martinez M, Kahles H, Seidl C, Böhme A, et al. Polymorphisms of CXCR3-Binding Chemokines in Type 1 Diabetes. Hum Immunol (2009) 70(7):552-5. doi: 10.1016/j.humimm.2009.04.031

97. Mehlotra RK, Cheruvu VK, Blood ZMJ, Benish RL, Lederman MM, Salata RA, et al. Chemokine (C-C Motif) Receptor 5 -2459 Genotype in Patients Receiving Highly Active Antiretroviral Therapy: Race-Specific Influence on Virologic Success. J Infect Dis 204(2):291-8.

98. Chen Y, Vaughan RW, Kondeatis E, Fortune F, Graham EM, Stanford MR, et al. Chemokine Gene Polymorphisms Associate With Gender in Patients With Uveitis. Tissue Antigens (2004) 63(1):41-5. doi: 10.1111/j.13990039.2004.00150.x

99. Seidler S, Zimmermann HW, Bartneck M, Trautwein C, Tacke F. AgeDependent Alterations of Monocyte Subsets and Monocyte-Related Chemokine Pathways in Healthy Adults. BMC Immunol (2010) 11:30. doi: 10.1186/1471-2172-11-30

100. Janesch P, Stulik L, Rouha H, Varga C, Steinhäuser J, Zerbs M, et al. AgeRelated Changes in the Levels and Kinetics of Pulmonary Cytokine and Chemokine Responses to Streptococcuspneumoniae in Mouse Pneumonia Models. Cytokine (2018) 111:389-97. doi: 10.1016/j.cyto.2018.09.012

Conflict of Interest: The authors declare that the research was conducted in the absence of any commercial or financial relationships that could be construed as a potential conflict of interest.

Publisher's Note: All claims expressed in this article are solely those of the authors and do not necessarily represent those of their affiliated organizations, or those of the publisher, the editors and the reviewers. Any product that may be evaluated in this article, or claim that may be made by its manufacturer, is not guaranteed or endorsed by the publisher.

Copyright (c) 2022 Pan, Kaminga, Kinra, Wen, Liu, Tan and Liu. This is an openaccess article distributed under the terms of the Creative Commons Attribution License (CC BY). The use, distribution or reproduction in other forums is permitted, provided the original author(s) and the copyright owner(s) are credited and that the original publication in this journal is cited, in accordance with accepted academic practice. No use, distribution or reproduction is permitted which does not comply with these terms. 